\title{
Intercalation of Molybdate Ions into Ni/Zn Layered Double Hydroxide Salts: Synthesis, Characterization, and Preliminary Catalytic Activity in Methyl Transesterification of Soybean Oil
}

\author{
Kamila Colombo, ${ }^{a}$ Swami A. Maruyama, ${ }^{b}$ Carlos I. Yamamoto ${ }^{a}$ and Fernando Wypych ${ }^{*, b}$ \\ ${ }^{a}$ Departamento de Engenharia Química and ${ }^{b}$ Departamento de Química, \\ Universidade Federal do Paraná, 81531-980 Curitiba-PR, Brazil
}

\begin{abstract}
This study reports the synthesis and characterization of a Ni/Zn layered double hydroxide salt intercalated with acetate ions and the subsequent replacement of the acetate ions with molybdate ions via an ion exchange reaction, conducted at two different $\mathrm{pH}$ values. Regardless of the $\mathrm{pH}$ employed during the synthesis, the basal spacing in the $\mathrm{Ni} / \mathrm{Zn}$ layered double hydroxide salt decreased from $13.08 \AA$ to approximately $9.5 \AA$, which agreed with intercalation of hydrated molybdate anions. The non-calcined material and the material submitted to heat treatment at $250{ }^{\circ} \mathrm{C}$ (basal spacing reduced to $7.35 \AA$, due to dehydration) were tested as catalyst for the methyl transesterification of soybean oil. Like sodium molybdate in homogeneous media, the solid materials were active catalysts. After reaction at $120^{\circ} \mathrm{C}$ for $4 \mathrm{~h}$, the materials afforded high conversions at an alcohol/soybean oil molar ratio of 35:1 and preserved the structure after three consecutive uses. In conclusion, intercalation of molybdate anion into the layered double hydroxide salt proved to be an efficient alternative to support the active species and transform a soluble catalyst into a solid with application in heterogeneous catalysis.
\end{abstract}

Keywords: layered double hydroxide salts, molybdate, intercalation, transesterification

\section{Introduction}

Layered materials have recently called the attention of the scientific community for their special properties. ${ }^{1}$ One class of these materials belongs to the family of natural and/or synthetic layered anion exchangers, which includes layered double hydroxides (LDH) and layered hydroxide salts (LHS). LHS have the general formula $\mathrm{M}^{2+}(\mathrm{OH})_{2-\mathrm{x}}\left(\mathrm{A}^{\mathrm{x}-}\right)_{\mathrm{x} / \mathrm{n}} \cdot \mathrm{yH}_{2} \mathrm{O}$, where $\mathrm{M}^{2+}$ represents a divalent metal such as $\mathrm{Mg}^{2+}, \mathrm{Ni}^{2+}$, $\mathrm{Zn}^{2+}, \mathrm{Ca}^{2+}, \mathrm{Cd}^{2+}, \mathrm{Co}^{2+}$, or $\mathrm{Cu}^{2+}$, and $\mathrm{A}^{\mathrm{x}-}$ is an anion that partially substitutes the hydroxyl groups of the structure. ${ }^{2,3}$ The most usual intercalated anions are $\mathrm{Cl}^{-}, \mathrm{NO}_{3}-\mathrm{CO}_{3}{ }^{2-}$, acetate, surfactants, and long-chain carboxylates like carboxylates derived from fatty acids.

LDHS are a class of materials derived from LHS in which two or even three metals occupy specific places in the layers of the material. LDHS have the formula $\mathrm{M}_{\mathrm{a}}{ }^{2+}{ }_{1-\mathrm{y}} \mathrm{M}_{\mathrm{b}}{ }^{2+}{ }_{\mathrm{y}}(\mathrm{OH})_{2-\mathrm{x}}\left(\mathrm{A}^{\mathrm{x}-}\right)_{\mathrm{x} / \mathrm{n}} \cdot \mathrm{yH}_{2} \mathrm{O}$, where $\mathrm{M}_{\mathrm{a}}{ }^{2+}$ and $\mathrm{M}_{\mathrm{b}}{ }^{2+}$ correspond to the two metals in the LDHS structure (examples: $\mathrm{Cu}, \mathrm{Ni}, \mathrm{Co}, \mathrm{Zn}, \mathrm{Mg}$, etc.). ${ }^{3-6}$

\footnotetext{
*e-mail: wypych@ufpr.br
}

Various structures have been described for LHS and LDHS; for example, glaukosphaerite: $(\mathrm{Cu}, \mathrm{Ni})_{2}(\mathrm{OH})_{2} \mathrm{CO}_{3}$, kolwezite: $(\mathrm{Cu}, \mathrm{Co})_{2}(\mathrm{OH})_{2} \mathrm{CO}_{3}$, rosasite: $(\mathrm{Cu}, \mathrm{Zn})_{2}(\mathrm{OH})_{2} \mathrm{CO}_{3}$, claraite: $(\mathrm{Cu}, \mathrm{Zn})_{2}(\mathrm{OH})_{2} \mathrm{CO}_{3} \cdot 4 \mathrm{H}_{2} \mathrm{O}$, kapellasite: $\mathrm{Cu}_{3} \mathrm{Zn}(\mathrm{OH})_{6} \mathrm{Cl}_{2}$, and haydeeite: $\mathrm{Cu}_{3} \mathrm{Mg}(\mathrm{OH})_{6} \mathrm{Cl}_{2}$. Many of these materials are of natural origin, and their structures have been detailed in the literature. ${ }^{7-10}$ However, due to the small number of studies involving this class of materials, they have few described potential applications. Molybdate anion has been intercalated into different $\mathrm{LDH}$, which has always led to materials with low crystallinity and small crystal sizes. ${ }^{11-14}$ Investigating intercalated molybdate is interesting: some studies have described the use of this ion in the catalytic disproportionation of hydrogen peroxide, ${ }^{11}$ oxidation of olefins, ${ }^{12}$ photodegradation of organic pollutants, ${ }^{13}$ electrocatalytic oxidation of water, ${ }^{14}$ and propane dehydrogenation, ${ }^{15}$ just to cite some examples.

Based on the results obtained by employing anhydrous sodium molybdate as catalyst during soybean oil esterification in homogeneous medium, ${ }^{16}$ this study aimed to evaluate the catalytic activity of molybdate ions intercalated into Ni/Zn LDHS. To this end, acetate ions were intercalated into $\mathrm{Ni} / \mathrm{Zn}$ LDHS and later replaced 
with molybdate ions. The molybdate-intercalated material was heated in an oven at $250{ }^{\circ} \mathrm{C}$ for $2 \mathrm{~h}$, and the calcined and non-calcined materials were characterized and used as catalyst in the methyl transesterification of soybean oil.

\section{Experimental}

\section{Synthesis of $\mathrm{Ni} / \mathrm{Zn}$ hydroxide acetate}

To synthesize Ni/Zn hydroxyacetate (NZHA), $4.07 \mathrm{~g}$ of $\mathrm{ZnO}$ (Synth, 99\%) was added to $200 \mathrm{~mL}$ of a $0.5 \mathrm{~mol} \mathrm{~L}^{-1}$ $\mathrm{Ni}\left(\mathrm{CH}_{3} \mathrm{COO}\right)_{2} \cdot 4 \mathrm{H}_{2} \mathrm{O}$ (Vetec, $\left.99 \%\right)$ solution. The reaction was maintained under magnetic stirring $(750 \mathrm{rpm})$ at $65{ }^{\circ} \mathrm{C}$ for seven days. The green material was separated by centrifugation (at $4000 \mathrm{rpm}$ for $4 \mathrm{~min}$ ), washed four times with distilled water, and dried in a laboratory oven at $65^{\circ} \mathrm{C}$ for $48 \mathrm{~h}$.

\section{Acetate/molybdate ion exchange}

In the synthesis of NZHA intercalated with molybdate anions, $0.5 \mathrm{~g}$ of NZHA was dispersed in approximately $200 \mathrm{~mL}$ of Milli-Q water. $\mathrm{NaOH}$ (Vetec, $99 \%)\left(1 \mathrm{~mol} \mathrm{~L}^{-1}\right)$ and $\mathrm{Na}_{2} \mathrm{MoO}_{4} \cdot 2 \mathrm{H}_{2} \mathrm{O}$ (Vetec, 99.5-103\%) prepared with twice the theoretical anion exchange capacity of NZHA $\left(\mathrm{Ni}_{3} \mathrm{Zn}_{2}(\mathrm{OH})_{8}\left(\mathrm{CH}_{3} \mathrm{COO}\right)_{2}: 285.1 \mathrm{mg}\right.$ of $\mathrm{MoO}_{4}^{-2}$ per $\left.\mathrm{g}\right)$ solutions were simultaneously added over this dispersion, dropwise. The reaction was conducted under constant magnetic stirring and $\mathrm{N}_{2}$ stream, at room temperature and $\mathrm{pH}=8.8$, for $1 \mathrm{~h}$. The product remained in contact with the mother solution under magnetic stirring for $24 \mathrm{~h}$. The pale green precipitate was separated by centrifugation, washed with Milli-Q water, and dried in a laboratory oven at $60{ }^{\circ} \mathrm{C}$ under vacuum for $48 \mathrm{~h}\left(\mathrm{NZHMoO}_{4}-8.8\right)$. Another compound was synthesized in a similar manner, but at $\mathrm{pH}=8.2\left(\mathrm{NZHMoO}_{4}-8.2\right)$.

\section{Calcination of the molybdate catalyst obtained at $\mathrm{pH}=8.8$}

Both materials intercalated with molybdate anions were calcined at $250{ }^{\circ} \mathrm{C}$ in a muffle furnace (EDG brand, model 3000) at a heating rate of $10^{\circ} \mathrm{C} \mathrm{min}^{-1}$, for $2 \mathrm{~h}$. The calcination step was conducted to dehydrate the intercalated molybdate anions without destroying the layered solid.

\section{Characterization of the materials}

The X-ray diffraction (XRD) measurements of the precursors were recorded after the materials were placed in glass or aluminum sample holders kept inside a Shimadzu diffractometer, model XRD-6000. CuK $\alpha$ radiation source of $\lambda=1.5418 \AA$, current of $30 \mathrm{~mA}$, and tension of $40 \mathrm{kV}$ were employed. The powdered samples were placed in the sample holders to avoid their displacement and the consequent shift in reflection positions. The powders were gently pressed with another planar material. The diffraction patterns were acquired with a dwell time of $2^{\circ} \mathrm{min}^{-1}$ and step of 0.02 degrees.

The Fourier transform infrared (FTIR) spectra were obtained in the transmission mode in a Bio-Rad spectrometer, Model FTS 3500GX, in KBr discs. A total of 32 scans were accumulated from 400 to $4000 \mathrm{~cm}^{-1}$, with resolution of $4 \mathrm{~cm}^{-1}$.

Simultaneous thermogravimetric analyses (TGA) and differential thermal analysis (DTA) were performed in a NETZSCH STA 449 F1 Jupiter analyzer under synthetic air flow of $50 \mathrm{~mL} \mathrm{~min}^{-1}$, in alumina crucibles, at a heating rate of $10^{\circ} \mathrm{C} \mathrm{min}^{-1}$. The temperatures ranged from 25 to $1000^{\circ} \mathrm{C}$.

For the Raman spectroscopy measurements, the materials were placed on a platinum plate of a Witec alpha 300R Confocal Raman microscope, and the samples were excited with a $\mathrm{He} / \mathrm{Ne}$ laser $(633 \mathrm{~nm})$. After calibration with silicon disc $\left(520.5 \mathrm{~cm}^{-1}\right)$, the spectra were registered between 100 and $4000 \mathrm{~cm}^{-1}$ with a nominal resolution of $0.02 \mathrm{~cm}^{-1}$.

Energy dispersive spectroscopy (EDS) was conducted with the aid of a microscope in a TESCAN VEGA3 LMU (EDS-Oxiford) apparatus by using the AZ Tech (Advanced) software, an SDD type detector of $80 \mathrm{~mm}^{2}$, and voltage of $15 \mathrm{kV}$. Powder samples were placed on the sample holder and fixed with commercial glue. The scans were acquired from 0 to $11 \mathrm{keV}$. After EDS analysis, the samples were metal sputtered. Micrographs were then obtained by scanning electron microscopy (SEM) accomplished with the same microscope.

The methyl transesterification of refined soybean oil with anhydrous methanol was carried out in a Buchiglassuster miniclave-drive batch reactor consisting of a 100-mL steel container coupled to a heat control system, model Julabo ${ }^{\circledR}$-HE4. The experiments were conducted by using $5 \%$ of catalyst in relation to the mass of oil, at a 35:1 methanol/soybean oil molar ratio, at $120^{\circ} \mathrm{C}$, for $4 \mathrm{~h}$. At the end of each reaction, the medium containing both the liquid and the solid phases was transferred to a 50 -mL centrifuge tube, and the phases were separated by centrifugation at $4500 \mathrm{rpm}$ for $10 \mathrm{~min}$. The supernatant was collected and submitted to rotary evaporation under reduced pressure at $65{ }^{\circ} \mathrm{C}$, which separated unreacted alcohol from the remaining reaction products.

The transesterification reactions in the presence of the calcined catalyst were performed in the same operating conditions mentioned previously. The catalyst recovered 
in the solid phase was separated from the reaction medium by centrifugation, repeatedly washed with hexane, filtered under reduced pressure, and dried in a laboratory oven for $12 \mathrm{~h}$, for further characterization and reuse. Experiments were also accomplished in the same conditions as the catalytic reactions but without the catalyst (thermal conversion). Considering that molybdate is the active material, one experiment was also carried out with $\mathrm{Na}_{2} \mathrm{MoO}_{4}$ only, in homogeneous medium. For comparison purposes, the amount of molybdate was calculated so that it would be the same as the amount of molybdate theoretically present in $\mathrm{NZHMoO}_{4}-8.8$. Because quantitative recovery of the catalysts was not possible and in order to maintain the same reaction conditions, the amounts of reagents employed in the reuse test were adapted according to the catalyst mass.

The esters were separated and quantified by gas chromatography according to the EN14103 procedure, developed for analysis of methylic biodiesel obtained from vegetable oils, using methyl nonadecanoate as standard. The separations were achieved in a SHIMADZU GC-210 gas chromatograph equipped with an AOC-500 flame ionization detector operating at $300{ }^{\circ} \mathrm{C}$ and a SUPELCOWAX capillary column $(30 \mathrm{~m} \times 0.25 \mathrm{~mm} \times 0.25 \mu \mathrm{m})$ operating at $200{ }^{\circ} \mathrm{C}$ with pressure of $120 \mathrm{kPa}$. Approximately $1 \mu \mathrm{L}$ of each sample was injected into the equipment at $25{ }^{\circ} \mathrm{C}$ with a split ratio of 100:1. The total run time was $43 \mathrm{~min}$.

\section{Results and Discussion}

The X-ray diffraction patterns of NZHA (Figure 1a) displayed the typical profile of a layered material with a sequence of (001) basal reflections, followed by reflections at $2 \theta=33.5^{\circ}$ and $59.8^{\circ}$, assigned to non-basal reflections indexed as 100 and 110 , respectively.

The reflections resembled saw teeth, which revealed a structural disorder along the stacked layers (turbostractivity). To minimize errors, the basal distance calculated for the NZHA reflection of largest possible order $(n=3)$ was 13.08 $\AA$, which agreed with the formula expected for the NZHA $\left(\mathrm{Ni}_{3} \mathrm{Zn}_{2}(\mathrm{OH})_{8}\left(\mathrm{CH}_{3} \mathrm{COO}\right)_{2} \cdot 3 \mathrm{H}_{2} \mathrm{O}\right) \cdot{ }^{17,18}$

After the acetate/molybdate ion exchange reaction, the basal distances decreased from $13.08 \AA$ to 9.56 and $9.48 \AA$ for $\mathrm{NZHMoO}_{4}-8.2$ and $\mathrm{NZHMoO}_{4}-8.8$, respectively. Maintenance of the two non-basal reflections (100 and 110) and of basal reflections with almost the same width evidenced that the compound retained its structure and confirmed the topotactic exchange reaction. The distance between two nickel metals is obtained from the 110 peak as $3.09 \AA$, which is consistent with the data obtained by extended X-ray absorption fine structure (EXAFS) (3.061 ̊̊). ${ }^{19}$

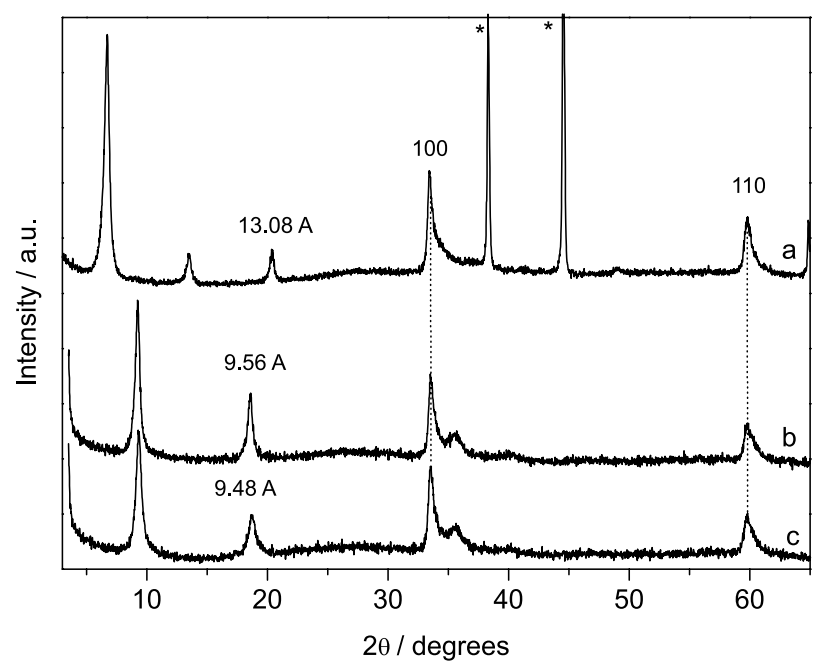

Figure 1. X-ray diffraction patterns of (a) NZHA; (b) $\mathrm{NZHMoO}_{4}-8.2$; and (c) $\mathrm{NZHMoO}_{4}-8.8$. *Aluminum from the sample holder.

In fact, the basal distances were consistent with the diameter of the molybdate anion, which is equal to $4.92 \AA(9.56-4.77 \AA$ (Brucite layer thickness) $=4.79 \AA$; $9.48-4.77 \AA$ (Brucite layer thickness) $=4.71 \AA$ ).$^{20}$ In fact, molybdate can intercalate along the direction of the $\mathrm{C} 3$ and $\mathrm{C} 2$ axis perpendicular to the layers, giving distances of 5.2 and $4.8 \AA$, respectively, ${ }^{21}$ which are close to the aforementioned values of 4.79 and $4.71 \AA$, respectively.

Fourier transform infrared spectroscopy (FTIR) also attested that acetate ions were exchanged for molybdate ions (Figure 2). The spectrum of NZHA (Figure 2a) displayed a broad band at $3400 \mathrm{~cm}^{-1}$, which is associated with the vibration of hydroxyls that establish hydrogen bonds with water molecules. Intense bands emerged at 1575 and $1399 \mathrm{~cm}^{-1}$ due to the presence of antisymmetric and symmetric stretching of carboxylate groups, respectively. The band at $1339 \mathrm{~cm}^{-1}$ corresponded to symmetric

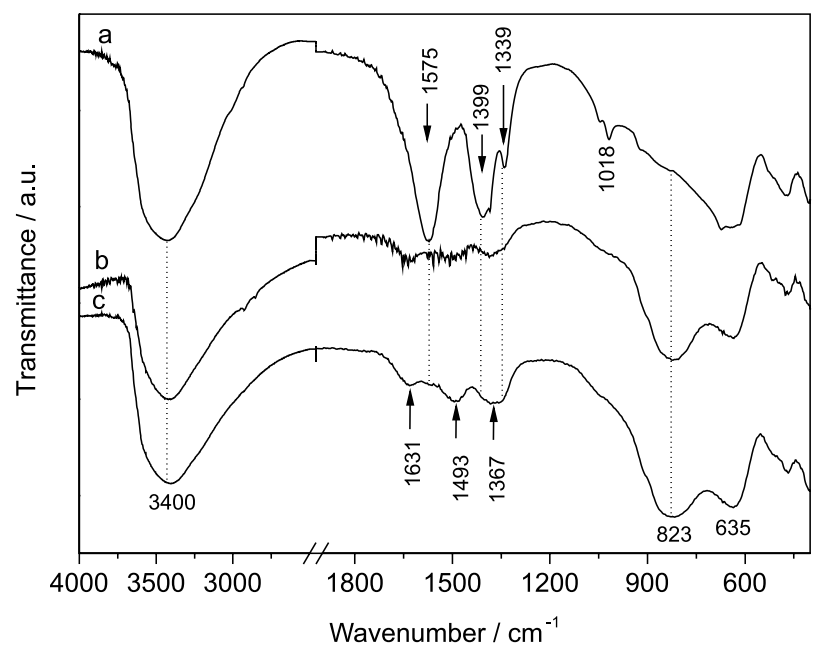

Figure 2. FTIR spectra of (a) NZHA; (b) $\mathrm{NZHMoO}_{4}-8.2$; and (c) $\mathrm{NZHMoO}_{4}-8.8$. 
deformation of the $-\mathrm{CH}_{3}$ group, and the band at $1018 \mathrm{~cm}^{-1}$ referred to rocking of the methyl group. ${ }^{22}$

After the exchange of acetate ions for molybdate ions, the intense bands assigned to the acetate ions were almost completely replaced with bands at 1631 (water bending), $1493,1367,823$, and $635 \mathrm{~cm}^{-1}$. The two latter bands were attributed to anti-symmetric and symmetric stretching vibrations of Mo-O bonds, while the other bands are probably attributed to carbonate anions. ${ }^{23}$ In general, the spectrum was virtually identical to the spectrum obtained after intercalation of molybdate ions into $\mathrm{Al}: \mathrm{Zn}$ and $\mathrm{Mg}: \mathrm{Zn}$ layered double hydroxides. ${ }^{24-26}$

Figure 3 presents the Raman spectra of NZHA and of the material obtained after ion exchange with molybdate ions in two different conditions: $\mathrm{NZHMoO}_{4}-8.2$ (Figure 3b) and $\mathrm{NZHMoO}_{4}-8.8$ (Figure 3c).

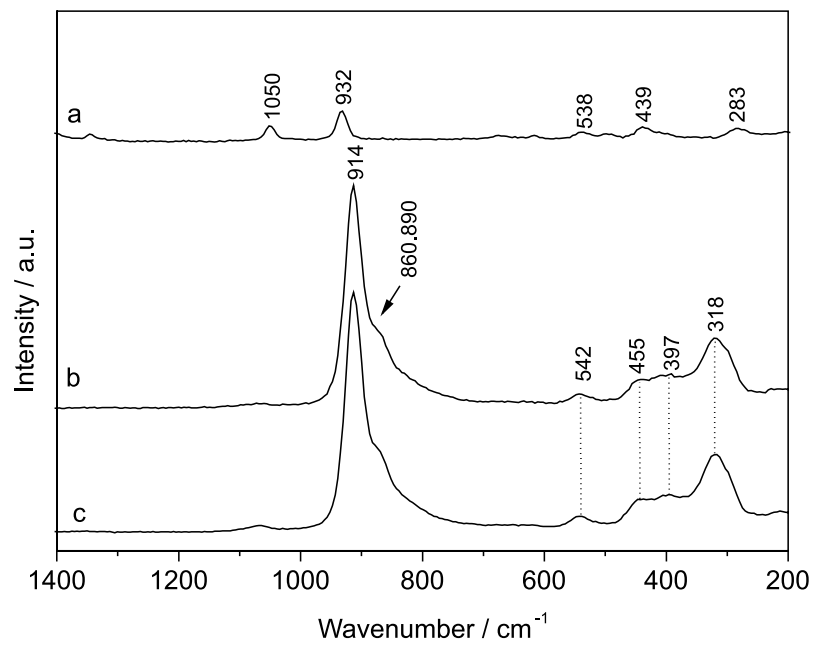

Figure 3. Raman spectra of (a) NZHA; (b) $\mathrm{NZHMoO}_{4}-8.2$; and (c) $\mathrm{NZHMoO}_{4}-8.8$.

The Raman spectra clearly showed that the position of the bands changed after the ion exchange reaction. Irrespective of the $\mathrm{pH}$ ( 8.8 or 8.2) used during ion exchange, the low-intensity bands at 1050 and $932 \mathrm{~cm}^{-1}$ in the spectrum of NZHA were replaced with intense bands at 914 (shoulders at 860 and $890 \mathrm{~cm}^{-1}$ ) and $318 \mathrm{~cm}^{-1}$, and less intense bands appeared at 542,455 , and $397 \mathrm{~cm}^{-1}$. The band at $914 \mathrm{~cm}^{-1}$ and the shoulders at $890 \mathrm{~cm}^{-1}$ were ascribed to the symmetric stretching modes (or hydrogen bonded) of the intercalated molybdate anions, whereas the shoulder at $860 \mathrm{~cm}^{-1}$ was attributed to the molybdate antisymmetric stretching mode. The band at $318 \mathrm{~cm}^{-1}$ was assigned to the $v_{4}$ bending mode of the molybdate anions, and the other bands were related to the NZHA structure. ${ }^{23-25}$

The TGA/DTA analyses of the compounds (Figure 4) revealed three mass loss events for NZHA (Figure 4a) with minima at 90,270 , and $326^{\circ} \mathrm{C}$ in the DTA curves.
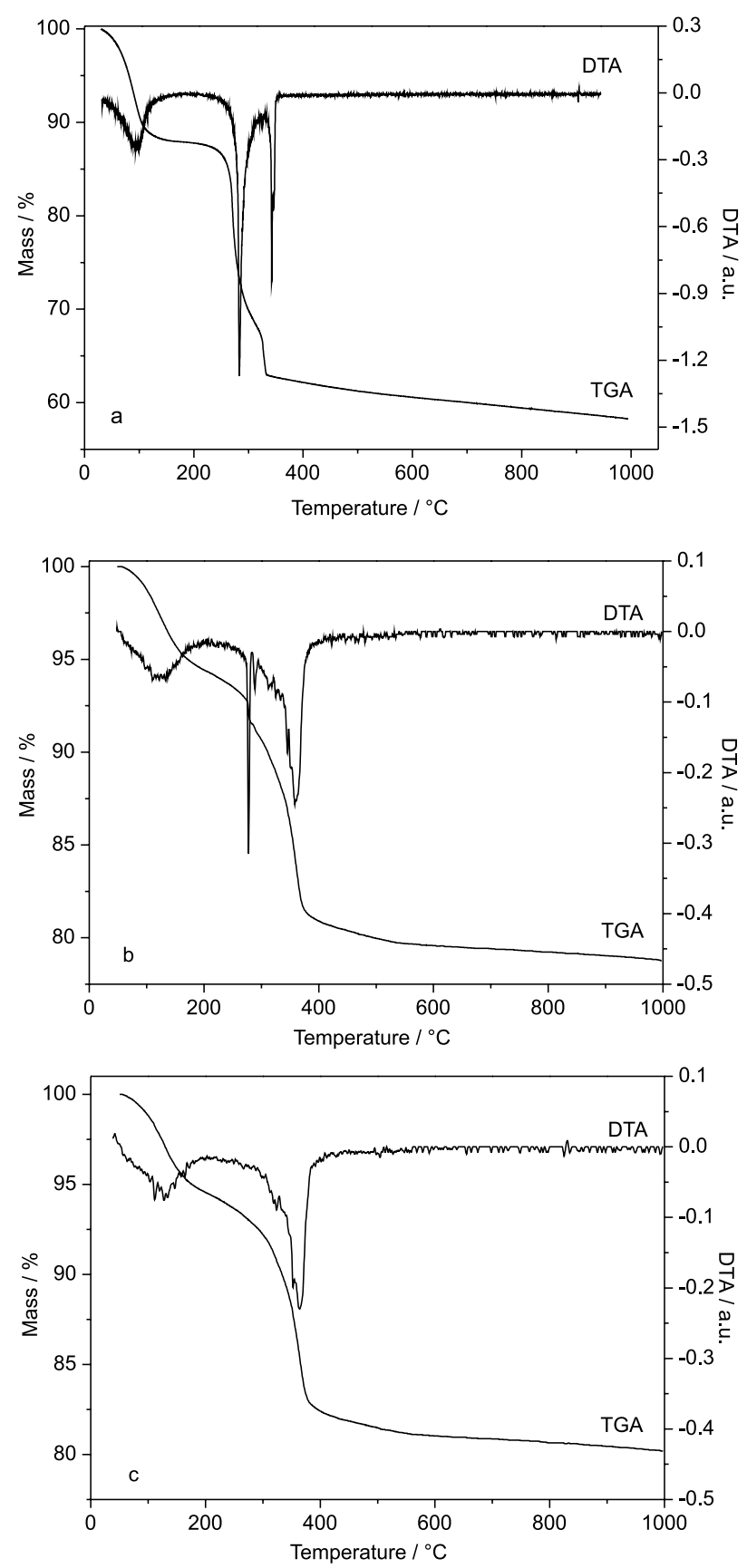

Figure 4. TGA/DTA curves of (a) NZHA; (b) $\mathrm{NZHMoO}_{4}-8.2$; and (c) $\mathrm{NZHMoO}_{4}-8.8$.

The content of mass loss up to $200{ }^{\circ} \mathrm{C}$ was $12.21 \%$, which corresponded to removal of moisture either adsorbed to or associated with acetate ions in the sample. The residual mass at $1000{ }^{\circ} \mathrm{C}$ was $58.26 \%$ (on dry basis, $66.36 \%$ ), which was close to the $68.96 \%$ value expected on the basis of the theoretical formula (on dry basis) predicted in the synthesis: $\mathrm{Ni}_{3} \mathrm{Zn}_{2}(\mathrm{OH})_{8}\left(\mathrm{CH}_{3} \mathrm{COO}\right)_{2}$ or even $\mathrm{Ni}_{0.75} \mathrm{Zn}_{0.50}(\mathrm{OH})_{2}\left(\mathrm{CH}_{3} \mathrm{COO}\right)_{0.50}$. The experimental residue investigated by $\mathrm{X}$-ray diffraction revealed the presence of $\mathrm{NiO}$ and $\mathrm{ZnO}$ only (not shown). 
The TGA/DTA curves obtained after the ion exchange reaction at two different $\mathrm{pHs}$ were different, and the amount of residues was greater than the amount of residue obtained for NZHA, as expected.

For the sample prepared at $\mathrm{pH} 8.2\left(\mathrm{NZHMoO}_{4}{ }^{-8.2}\right)$ (Figure $4 \mathrm{~b}$ ), the same three DTA peaks emerged, but the mass loss up to $200{ }^{\circ} \mathrm{C}$ was $5.57 \%$, whilst the total residue at $1000{ }^{\circ} \mathrm{C}$ corresponded to $78.77 \%$ ( $83.42 \%$ on dry basis). This value was slightly lower than the value theoretically predicted for complete acetate/molybdate ion exchange $\left(\mathrm{Ni}_{3} \mathrm{Zn}_{2}(\mathrm{OH})_{8}\left(\mathrm{MoO}_{4}\right)\right)$, for which the content of residues would be $87.84 \%$ (deviation of $5.3 \%$ ). The sharp peak at $278^{\circ} \mathrm{C}$ in the DTA curve evidenced small contamination of the material with acetate ions. This peak also arose in the DTA curve of NZHA (Figure 4a). The DTA curve of the material obtained at $\mathrm{pH} 8.8\left(\mathrm{NZHMoO}_{4}-8.8\right)$ (Figure 4c) displayed two peaks $\left(130\right.$ and $\left.360{ }^{\circ} \mathrm{C}\right)$. The mass loss up to $200{ }^{\circ} \mathrm{C}$ was $5.4 \%$, attributed to loss of water, and the residue obtained at $1000^{\circ} \mathrm{C}$ corresponded to $80.19 \%$ of the initial mass ( $84.8 \%$ on dry basis). This residual value was close to the theoretical value $(88.05 \%$ ) (deviation of $3.7 \%$ ), demonstrating that the acetate ions were almost entirely replaced by molybdate ions. In both $\mathrm{NZHMoO}_{4}-8.2$ and $\mathrm{NZHMoO}_{4}-8.8$, the content of residues was systematically lower than the theoretical value, probably as a result of $\mathrm{MoO}_{3}$ volatilization, which occurs at temperatures higher than $700{ }^{\circ} \mathrm{C} .{ }^{27}$

Figure 5 illustrates the SEM and EDS results. As expected for materials with layered structures, the crystals of all the materials resembled plates.
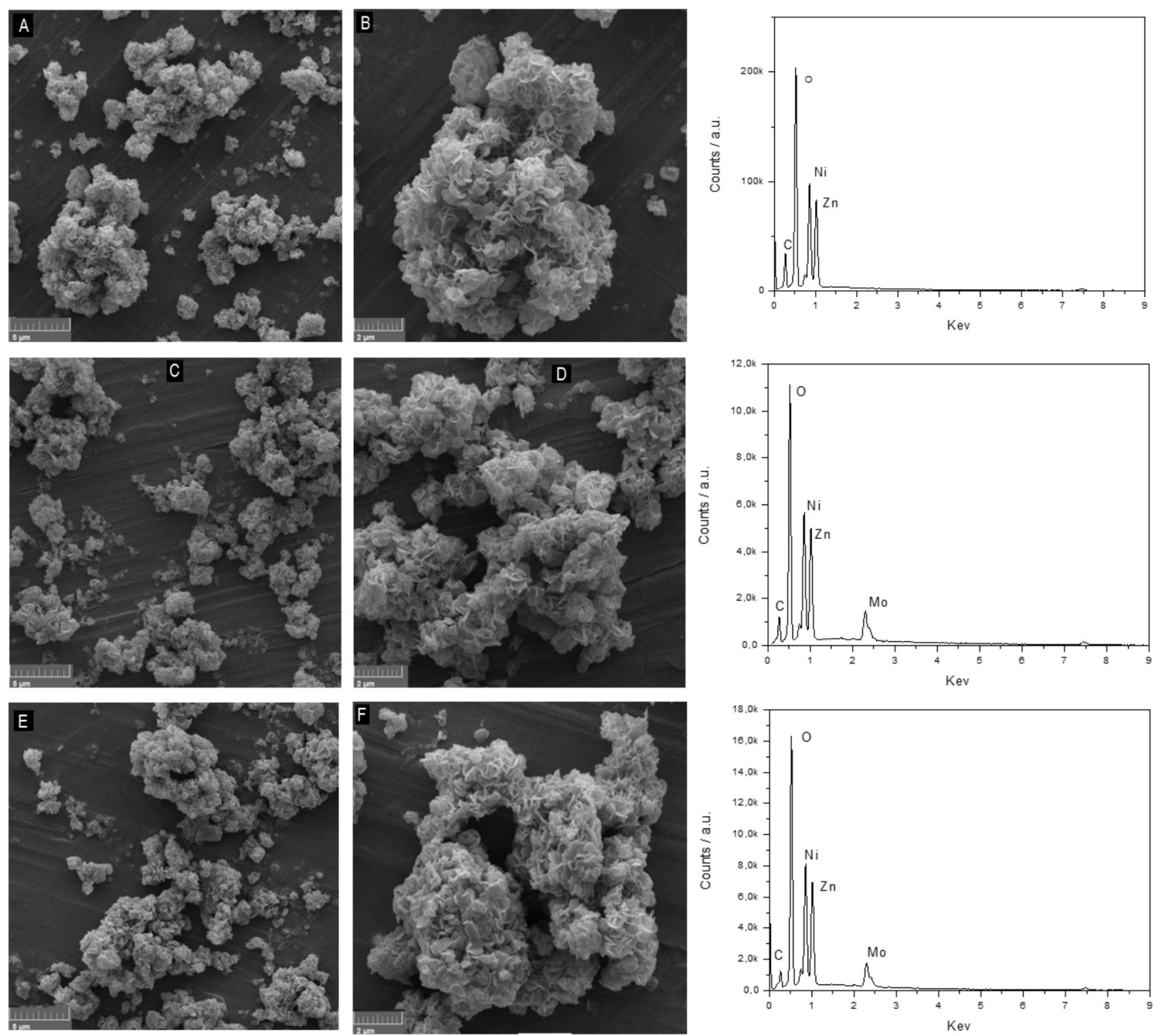

Figure 5. SEM images (left and middle sides: magnifications of $\times 10 \mathrm{k}$ and $\times 20 \mathrm{k}$ ) and EDS spectra (right) of (A, B) NZHA; (C, D) NZHMoO -8.2 ; and (E, F) $\mathrm{NZHMoO}_{4}-8.8$. 
The particle dimensions were in the order of a few microns over the planes of the layered crystals and submicrometric along the stacked layers.

For NZHA and for $\mathrm{NZHMoO}_{4}-8.2$ and $\mathrm{NZHMoO}_{4}-8.8$, whose theoretical formulas are $\mathrm{Ni}_{3} \mathrm{Zn}_{2}(\mathrm{OH})_{8}\left(\mathrm{CH}_{3} \mathrm{COO}\right)_{2}$. $\mathrm{nH}_{2} \mathrm{O}$ and $\mathrm{Ni}_{3} \mathrm{Zn}_{2}(\mathrm{OH})_{8}\left(\mathrm{MoO}_{4}\right) \cdot \mathrm{nH}_{2} \mathrm{O}$, respectively, the theoretical $\mathrm{Ni} / \mathrm{Zn}$ ratios should be 1.5 . However, the experimental $\mathrm{Ni} / \mathrm{Zn}$ ratios were $1.2,1.0$, and 1.4 for NZHA, $\mathrm{NZHMoO}_{4}-8.2$, and $\mathrm{NZHMoO}_{4}-8.8$, respectively, which were relatively distant from the expected value. The formula of the materials was close to $\mathrm{Ni}_{0.70} \mathrm{Zn}_{0.60}(\mathrm{OH})_{2}\left(\mathrm{~A}^{\mathrm{n}-}\right)_{2 \times / \mathrm{n}}$. $\mathrm{nH}_{2} \mathrm{O}$ (where $\mathrm{A}=\mathrm{CH}_{3} \mathrm{COO}$ or $\mathrm{MoO}_{4}^{-2}$ ), which resembled the formula obtained for the same system prepared by the mechanochemical method. ${ }^{28}$

After ion exchange, molybdenum became detectable in the samples even though its amount was below the expected value. Partial exchange of acetate ions for molybdate ions may have taken place, although neither FTIR nor Raman spectroscopy detected acetate ions.

The expected $\mathrm{Zn} / \mathrm{Mo}$ and Ni/Mo molar ratios in the expected formulas $\left(\mathrm{Ni}_{3} \mathrm{Zn}_{2}(\mathrm{OH})_{8}\left(\mathrm{MoO}_{4}\right)\right), 2 / 1=2$ and $3 / 1=3$, respectively, were indeed 3.5 and 3.5 in NZHMoO4-8.2 (a), and 2.9 (b) and 4.2 in NZHMoO4-8.8 (c). Hence, the molybdate ion content was sub-stoichiometric, and the materials were probably contaminated with acetate or carbonate ions. In spite of the similarities, $\mathrm{NZHMoO}_{4}-8.8$ showed the higher proportion of molybdate based on the EDS analysis and this material was chosen for the investigation as catalyst in the transesterification of soybean oil with methanol (Figure 6).

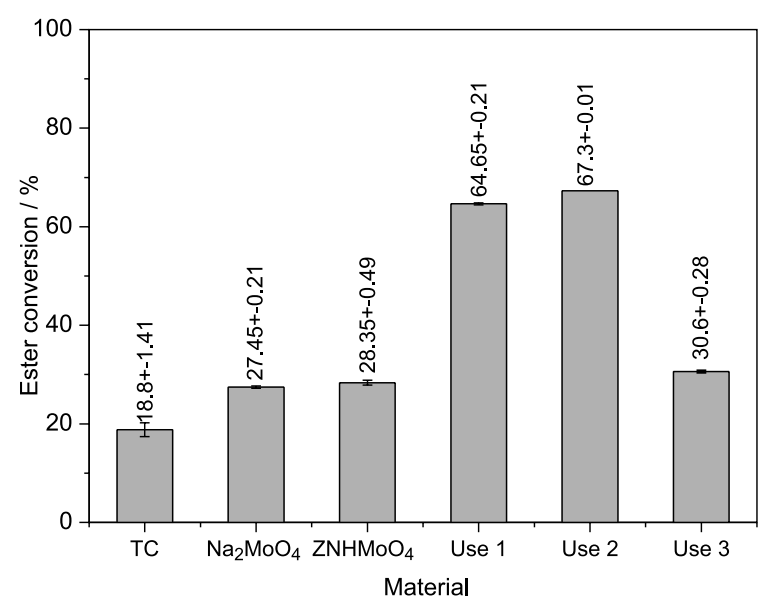

Figure 6. Ester contents obtained after soybean oil transesterification with methanol: $\mathrm{TC}=$ thermal conversion; $\mathrm{Na}_{2} \mathrm{MoO}_{4}=$ pure sodium molybdate (content that theoretically would exist in the amount of $\mathrm{NZHMoO}_{4}-8.8$ used in the reaction); Use 1, 2 and 3 = first use, first reuse, and second reuse of $\mathrm{NZHMoO}_{4}-8.8-\mathrm{c}$.

$\mathrm{NZHMoO}_{4}-8.8$ submitted to thermal activation at $250{ }^{\circ} \mathrm{C}\left(\mathrm{NZHMoO}_{4}-8.8-\mathrm{c}\right)$ afforded higher ester content than non-calcined $\mathrm{NZHMoO}_{4}-8.8$ (64.65 vs. 28.35\%). For the first two reactions using the same catalyst, the ester content did not change significantly (Use 1: $64.65 \%$ and Use 2: $67.3 \%$ ). However, on a second catalyst reuse, the ester value reduced sharply (Use 3: 30.6\%). A new thermal activation might re-activate the catalyst employed during reuse 2 , which will be the object of subsequent studies. The ester content obtained in the absence of the catalyst was $18.8 \%$, and $\mathrm{NZHMoO}_{4}-8.8$ without calcination or sodium molybdate did not contribute to the conversion of soybean oil to esters significantly (28:35 vs. 27.45\%).

Figure 7 contains the X-ray diffraction patterns of $\mathrm{NZHMoO}_{4}-8.8$ prior to calcination, after calcination at $250{ }^{\circ} \mathrm{C}\left(\mathrm{NZHMoO}_{4}-8.8-\mathrm{c}\right)$, and after three uses in the transesterification of soybean oil with methanol.

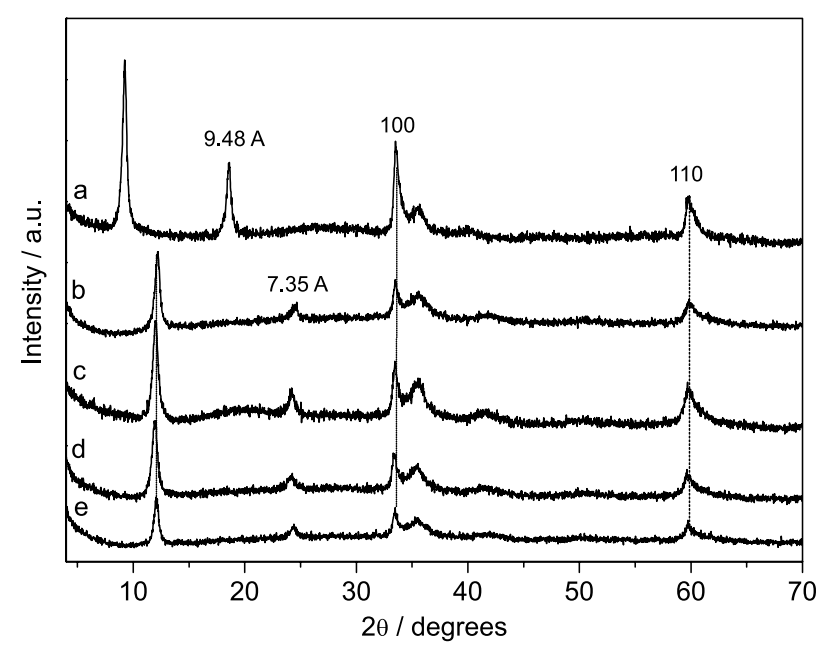

Figure 7. X-ray diffraction patterns of $\mathrm{NZHMoO}_{4}-8.8$ (a) before and (b) after calcination at $250^{\circ} \mathrm{C}\left(\mathrm{NZHMoO}_{4}-8.8-\mathrm{c}\right)$, (c) after transesterification of soybean oil with methanol, (d) first reuse, (e) second reuse.

$\mathrm{NZHMoO}_{4}-8.8$ had a basal distance of $9.48 \AA$ (Figure 7a). In $\mathrm{NZHMoO}_{4}-8.8$-c, this distance decreased to $7.35 \AA$ (Figure 7b). Considering that at $250{ }^{\circ} \mathrm{C}$ $\mathrm{NZHMoO}_{4}-8.8$-c was in the anhydrous form (see TGA curve in Figure 4c), the molybdate ion was most probably dehydrated and grafted to the LHS layers, giving rise to Mo-O-Ni (or $\mathrm{Zn}$ ) bonds and shorter basal distance. Despite the supposed grafting reactions, $\mathrm{NZHMoO}_{4}-8.8-\mathrm{c}$ still preserved the layered structure, as judged from the maintenance of the non-basal reflections, indexed as 100 and 110 , in all the X-ray diffraction patterns.

After being used in the transesterification of soybean oil with methanol for the first time, the recovered $\mathrm{NZHMoO}_{4}-8.8$-c retained its structure. The basal distance was $7.28 \AA$ (Figure 7c), which remained virtually unaltered if one considers the experimental error of the equipment. Basal distance errors in the order of decimal 
points are expected, especially when only reflections at low angles arise.

Figure 8 shows the FTIR spectra of $\mathrm{NZHMoO}_{4}-8.8$ (Figure 8a), $\mathrm{NZHMoO}_{4}-8.8$-c (Figure 8b) and $\mathrm{NZHMoO}_{4}-8.8$-c after transesterification of soybean oil with methanol: first reuse (Figure 8c), second reuse (Figure 8d). Before calcination, $\mathrm{NZHMoO}_{4}-8.8$ displayed bands at $1631,1493,1367,823$, and $635 \mathrm{~cm}^{-1}$. After calcination, $\mathrm{NZHMoO}_{4}-8.8$-c presented bands at $1625,1495,1374$, and $1334 \mathrm{~cm}^{-1}$. These bands remained unchanged after three uses, demonstrating that $\mathrm{NZHMoO}_{4}-8.8$-c structure remained mostly intact after three catalytic cycles.

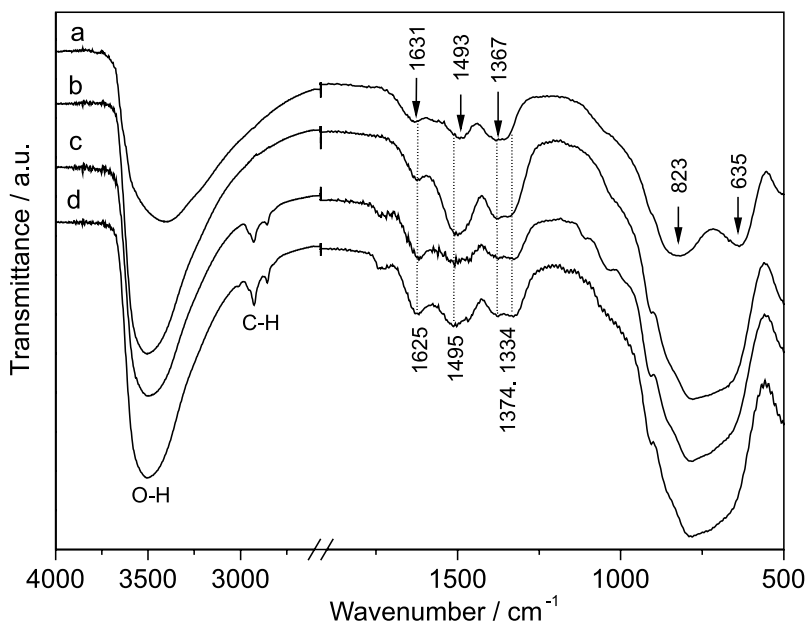

Figure 8. FTIR spectra of (a) $\mathrm{NZHMoO}_{4}^{-} 8.8$, (b) $\mathrm{NZHMoO}_{4}-8.8$-c; and $\mathrm{NZHMoO}_{4}-8.8$-c after transesterification of soybean oil with methanol: (c) first reuse, (d) second reuse.

The bands present in the region below $1000 \mathrm{~cm}^{-1}$ broadened because the crystallinity of $\mathrm{NZHMoO}_{4}-8.8-\mathrm{c}$ decreased and probable formation of extra bands attributed to Mo-O-Ni (or $\mathrm{Zn}$ ) bonds, which coalesced to a single and broad band. The Raman spectrum of $\mathrm{NZHMoO}_{4}-8.8-\mathrm{c}$ (not shown) indicated bands at 914 and $335 \mathrm{~cm}^{-1}$, slightly shifted from the band of the non calcined $\mathrm{NZHMoO}_{4}-8.8$ (band at $318 \mathrm{~cm}^{-1}$ ).

The other bands observed in the region of $2800-2900 \mathrm{~cm}^{-1}$ were assigned to small contamination with organic matter, which consists of residual products such as esters and fatty acids, which were not totally removed through the adopted washing procedure.

\section{Conclusion}

Molybdate anions were intercalated into layered $\mathrm{Ni} / \mathrm{Zn}$ hydroxide salts, replacing the previously intercalated acetate anions. Before and after exchange of the acetate anions for the molybdate anions at $\mathrm{pH}=8.8$, the compositions of the materials were close to $\mathrm{Ni}_{3} \mathrm{Zn}_{2}(\mathrm{OH})_{8}\left(\mathrm{CH}_{3} \mathrm{COO}\right)_{2} \cdot \mathrm{nH}_{2} \mathrm{O}$ and $\mathrm{Ni}_{3} \mathrm{Zn}_{2}(\mathrm{OH})_{8}\left(\mathrm{MoO}_{4}\right) \cdot \mathrm{nH}_{2} \mathrm{O}$, respectively. XRD aided monitoring of the acetate/molybdate exchange reactions and the basal spacing changed from $13.08 \AA$ to approximately $9.5 \AA$, which is expected for the intercalation of hydrated molybdate anions. After calcination at $250{ }^{\circ} \mathrm{C}$, the basal distance of the material was reduced to $7.35 \AA$, evidencing that the molybdate anions were dehydrated and probably grafted to the LHS layers at this temperature.

The material intercalated with molybdate anions at $\mathrm{pH}=8.8, \mathrm{NZHMoO}_{4}-8.8$, and calcined at $250{ }^{\circ} \mathrm{C}$ ( $\mathrm{NZHMoO}_{4}-8.8$-c) gave good conversion when the reaction was conducted at $120^{\circ} \mathrm{C}$, for $4 \mathrm{~h}$, at an alcohol/soybean oil molar ratio of 35:1. One important aspect of this preliminary investigation was that although the calcined $\mathrm{NZHMoO}_{4}-8.8$ gave lower conversion to esters during the reuse experiments, it was easily removed from the reaction medium and had its structure preserved. Therefore, this class of compounds could lead to new catalysts not only for the production of ester but also for other uses. Other systems like $\mathrm{Zn} / \mathrm{Co}$ and $\mathrm{Zn} / \mathrm{Cu}$ and exfoliation of all systems to expose intercalated molybdate anions are under investigation and will be described in a forthcoming publication.

\section{Acknowledgments}

The authors thank CNPq (Conselho Nacional de Desenvolvimento Científico e Tecnológico), CAPES (Coordenação de Aperfeiçoamento de Pessoal de Nível Superior), FINEP (Financiadora de Estudos e Projetos), and ANP (Agencia Nacional do Petróleo) for financial support. K. C. and S. A. M. thank also CAPES for the $\mathrm{PhD}$ and post-doctorate scholarships (S. A. M., Proc. No. 502099/2014-3).

\section{References}

1. Theiss, F. L.; Ayoko, G. A.; Frost, R. L.; Appl. Surf. Sci. 2016, 383, 200.

2. Kandare, E.; Hossenlopp, J. M.; Inorg. Chem. 2006, 45, 3766.

3. Arizaga, G. G. C.; Satyanarayana, K. G.; Wypych, F.; Solid State Ionics 2007, 178, 1143.

4. Yamanaka, S.; Ando, K.; Ohashi, M.; Mater. Res. Soc. Symp. Proc. 1994, 371, 131.

5. Rojas, R.; Ulibarri, M. A.; Barriga, C.; Rives, V.; Appl. Clay Sci. 2010, 49, 176.

6. Tavares, S. R.; Vaiss, V. S.; Wypych, F.; Leitão, A. A.; Appl. Clay Sci. 2015, 114, 103.

7. Perchiazzi, N.; Merlino, S.; Eur. J. Mineral. 2006, 18, 787.

8. Perchiazzi, N.; Z. Kristallogr. Suppl. 2006, 23, 505.

9. Krause, W.; Bernhardt, H. J.; Braithwaite, R. S. W.; Kolitsch, U.; Pritchard, R.; Mineral. Mag. 2006, 70, 329. 
10. Malcherek, T.; Schluter, J.; Acta Crystallogr., Sect. B: Struct. Sci., Cryst. Eng. Mater. 2007, 63, 157.

11. Wahlen, J.; Vos, D. E.; Sels, B. F.; Nardello, V.; Aubry, J.; Alsters, P. L.; Jacobs, P. A.; Appl. Catal. A 2005, 293, 120.

12. Thao, N. T.; Trung, N. D.; Long, D. V.; Catal. Lett. 2016, 146, 918.

13. Mohapatra, L.; Parida, K.; Satpathy, M.; J. Phys. Chem. C 2012, 116, 13063.

14. Han, N.; Zhao, F.; Li, Y.; J. Mater. Chem. A 2015, 3, 16348.

15. Mitchell, P. C. H.; Wass, S. A.; Appl. Catal. A 2002, 225, 153.

16. Nakagaki, S.; Bail, A.; Santos, V. C.; Appl. Catal. A 2008, 351, 267.

17. Rajamathi, M.; Kamath, P. V.; Seshadri, R.; J. Mater. Chem. 2000, 10, 503.

18. Rajamathi, J. T.; Raviraj, N. H.; Ahmebd, M. F.; Rajamathi, M.; Solid State Sci. 2009, 11, 2080.

19. Tessier, C.; Guerlou-Demourgues, L.; Faure, C.; Demourguesa, A.; Delmasa, C.; J. Mater. Chem. 2000, 10, 1185.
20. Ardau, C.; Frau, F.; Dore, E.; Lattanzi, P.; Appl. Clay Sci. 2012, 65-66, 128.

21. Twu, J.; Dutta, P. K.; Chem. Mater. 1992, 4, 398.

22. Biswick, T.; Jones, W.; Pacula, A.; Serwicka, E.; Podobinski, J.; Solid State Sci. 2009, 11, 330.

23. Palmer, S. J.; Frost, R. L.; Ayoko, G.; Nguyen, T.; J. Raman Spectrosc. 2008, 39, 395.

24. Rives, V.; Ulibarri, M. A.; Coord. Chem. Rev. 1999, 181, 61.

25. Palmer, S. J.; Soisonard, A.; Frost, R. L.; J. Colloid Interface Sci. 2009, 329, 404.

26. Dobrea, I. D.; Ciocan, C. E.; Dumitriu, E.; Popa, M. I.; Petit, E.; Hulea, V.; Appl. Clay Sci. 2015, 104, 205.

27. Saburi, T.; Murata, H.; Suzuki, T.; Fujii, Y.; Kiuchi, K.; J. Plasma Fusion Res. 2002, 781, 1.

28. Thomas, N.; Mater. Res. Bull. 2012, 47, 3568.

Submitted: August 1, 2016

Published online: November 11, 2016 